\title{
Activity-Based Costing And The Theory Of Constraints: Using Time Horizons To Resolve Two Alternative Concepts of Product Cost
}

Ralph B. Fritzsch, (ffritr@nexus.mwsu.edu), Midwestern State University

\begin{abstract}
Activity-based costing and the Theory of Constraints have generated a substantial literature that reflects the importance of these topics with practitioners. These two methods appear to represent conflicting viewpoints of product cost. Rather than trying to resolve the question of "who's right", each method is examined with respect to its implicit assumptions about time horizons. The Theory of Constraints emerges as a shortrun decision tool while Activity-Based Costing has its primary application in strategic planning and control. The problems associated with these methods if time horizons change are examined and suggestions for an integrated approach incorporating elements of both methods are presented.
\end{abstract}

\section{Introduction}

I n 1987, Theodore Johnson and Robert Kaplan published Relevance Lost: The Rise and Fall of Management Accounting, their landmark criticism of traditional product cost accounting techniques. In it they questioned the usefulness of traditional product cost data for management decision-making. Their criticism centers on the use of outmoded cost allocation techniques that fail to reflect current production methods and cost patterns. Two basic alternatives have emerged as possible alternatives to the conditions described by Johnson and Kaplan. The

Readers with comments or questions are encouraged to contact the authors via e-mail. first, originated by Kaplan, is called activitybased cost $(\mathrm{ABC})$ management. It attempts to overcome the problems associated with traditional absorption cost accounting through an improved system of building up product costs based on their utilization of basic activities associated with the manufacturing process. The other alternative, perhaps most completely described by Eliyahu Goldratt, builds on the just-in-time inventory management and pull-through manufacturing methodologies developed by the Japanese. Known as the Theory of Constraints, it denies the relevance of product costs as a basis for decision-making in most modern production environments. 
My students recently observed after being exposed to $\mathrm{ABC}$ in cost accounting and to Goldratt in production management, the issues are all the same but the answers are all different. Faced with this conflict, the normal reaction is to ask which approach is correct. This same "who's right?" approach to these two alternatives was also the one taken by the National Association of Accountants when it examined these two alternatives during its Global Solutions II seminar held in May 1990. This article will briefly examine each of these two methods with particular attention to their underlying assumptions regarding the nature of product cost and their weaknesses in certain decision environments. It will then demonstrate that these assumptions represent cost concepts suited to decision situations having different time horizons (short-run vs. long run). They are thus not mutually exclusive but rather represent pieces of a general approach to problem solving. It concludes with a suggested general approach to product costing that encompasses both methods.

\section{Activity-Based Costing and the Theory of Constraints: Two Alternative Views of Prod- uct Cost}

\section{A. Activity-Based Costing}

Overhead costs have traditionally been allocated to product from a single plant-wide cost pool or from cost pools defined for organizational (departmental) sub-units. Because all types of costs are accumulated in the same cost pool, it is difficult to identify an allocation base that is causally related all or even a majority of them. Cost is allocated based on a directly measurable product characteristic, which usually correlates with product volume (such as direct labor cost or hours, or machine hours). Activity-based costing (or, activity-based accounting) uses manufacturing process activities as the basic unit for the accumulation of indirect manufacturing cost. Instead of using the traditional approach described above, indirect product costs are allocated based on utilization of these activities. Activities cost allocations are made by identifying "cost drivers" for each activity cost pool. A valid cost driver is causally related to the associated activity cost pool and as such provides a means of measuring the activity costs to be charged to a particular product. Proponents of $\mathrm{ABC}$ cite two major advantages in this approach. First, because all costs in a specific pool relate to a particular activity, it is far easier to identify a causally related allocation base or cost driver than under the traditional system. Second, by separately identifying activities, $\mathrm{ABC}$ can better apply costs related to some activities that are not driven by production volume. Examples would be costs that relate to number of batches produced or specific characteristics of the product itself, such as number of components. Cooper $(1990,78)$ identifies five steps in the design of an $\mathrm{ABC}$ accounting system. The first step is the aggregation of individual actions into activity pools. The actions that are included in each pool are traced or "driven" by a single cost driver. "Unfortunately, as more and more actions are aggregated into an activity, the ability of a cost driver to accurately trace the resources consumed by products decreases." After defining the cost pools, the level of aggregation used in reporting the costs associated with each activity is determined and the segments of the production process to which costs will be traced ("activity centers") are identified. The final two steps are the identification of cost drivers used to trace costs to each activity center (first-stage cost drivers) and cost drivers used to trace costs from activity centers to individual units of product (second stage cost drivers). Cooper stresses the importance of the selection of the proper type and number of cost pools and their associated cost drivers as an important consideration in avoiding distortion of final product costs.

As can be seen from the brief summary of $\mathrm{ABC}$ costing given above, the success of an $\mathrm{ABC}$ system is dependent on how activity pools and related cost drivers are selected. According to Roth and Borthick $(1991,39)$, these choices must define a cost system which is in accordance with two basic assumptions which are implicit in an $\mathrm{ABC}$ system. First, the costs in a given activity pool must be traceable using the same cost driver and as such must be highly correlated with 
each other and with the cost driver. One of the major problems in designing an $\mathrm{ABC}$ system, as described above, is to define a reasonably small number of cost pools without violating this assumption. Second, the costs in a given activity pool must vary proportionately to the cost driver associated with that pool. This implies that all costs are linear with respect to the applicable cost driver and that all costs are variable with respect to the activity used as a driver. Activity-based costing originally provided for treatment of some costs as "facility level" activities. These costs were to consist of the fixed costs associated with plant and equipment and were not to be allocated to product. However, in practice Cooper (1990, 4) found that all manufacturing cost pools were being allocated. Even if facilities costs are treated separately, costs in other activity pools may be fixed or mixed with respect to their various cost drivers. Assigning all these costs to product as if they are strictly variable thus violates the proportionality assumption inherent in $\mathrm{ABC}$.

\section{B. The Theory of Constraints}

Eliyahu Goldratt and Robert Fox are the authors of two books - The Race and The Goal - that contain a broad survey of "new" manufacturing topics such as just-in-time inventory systems and total quality management. The Theory of Constraints, as developed in these and other works by these authors, deals with the method of scheduling production through an existing facility in a way which will achieve maximum profitability through the maximization of output. As a proponent of just-in-time inventory systems, Goldratt achieves this by using a pull-through production management system that minimizes work-in-process inventories. In a pull-through system, product moves into production or from work station to work station only as capacity becomes available to begin working on it. Each work station signals the station that precedes it when it is ready to receive more product, hence the name pull-through. Production capacity in a pull-through system is determined by the capacity of that portion of the manufacturing process that acts as the constraint on throughput. All other activities in the process are paced by this restraining element or constraint to avoid the accumulation of intermediate work-in-process inventory. Traditional "push-through" systems push product into production according to a predetermined schedule. Each workstation processes product as fast as possible without regard for the ability of subsequent processing steps to keep up. The result is a build-up of partially completed work in process. In addition to tying up working capital, Goldratt demonstrates that this build-up has negative effects on the ability to control product quality and on throughput time for specific orders.

In Goldratt's view, only direct materials costs should be associated with product. Hornegren $(1991,292)$ refers to this concept of product cost as "super-variable cost". All other costs, including all categories of manufacturing labor, are fixed and remain unaffected by the level or type of product produced. Because only direct materials are charged to product, all problems of overhead allocations and the segregation of direct and indirect labor are eliminated. Goldratt argues $(1992,38)$ that the whole concept of product cost and product profitability are outmoded cost accounting concepts that had relevance in the early twentieth century piecework environment but which now just "get in the way" of sound management decisions. If almost all costs are fixed as assumed in this method, it also follows that maximization of throughput (and total revenue) will maximize profits because contribution margins will be nearly equal to unit revenue. Visualized in terms of the basic costvolume-profit model, Goldratt's view of the production process represents a system with very high operating leverage - high fixed costs and almost no variable or direct product costs.

\section{The Time-Relativity of Fixed and Variable Costs}

From the description of activity-based accounting and the theory of constraints presented above, it should be apparent that these two methodologies are based on opposing views of the nature of product cost. Activity-based 
costing assumes that all costs can be traced to product and that they will vary in proportion to applicable cost drivers. The theory of constraints argues that costs are almost all fixed and "sunk" with respect to product choice and production level decisions and that cost accounting systems which attempt to relate them to product just "get in the way". At this point, it seems logical to question which approach is correct. The answer is that they are both correct - sometimes. However, before examining this answer further it will be necessary to discuss fixed and variable costs and how they change as the time span associated with them changes.

Economists classify decision situations and their related costs as being either short-run or long-run. In the short-run, most capitalrelated inputs (factors of production) are fixed while others like labor and materials are variable. In the long run, all inputs including physical plant can be varied. Some authors also include what is called a very short-run case in which all inputs are fixed and a very long-run case in which inputs such as technology and regulatory constraints can vary. Applying these concepts to a production situation, this means that if we are deciding what to produce next week we are constrained by the level and type of plant and equipment and labor force available and by the availability of materials in inventory or from our suppliers. If we are talking about what to produce five years from now, alternatives involving major changes in production capacity and methods, in labor force composition, and in the type and quantity of materials used can be considered. The assumptions about cost behavior inherent in activity-based costing thus approximate the long-run case described above in which all costs are variable. The Theory of Constraints is based on the assumption that all input costs except materials are fixed, which corresponds to the very short-run situation described above. Because each method is associated with a particular time horizon, it would be anticipated that it would apply be best applied to decisions involving the same time horizons and poorly or not at all in decisions where time horizons are different. To determine if this is the case, the applicability of Activity Based Costing in short run decisions and the Theory of constraints to long-run decisions are now examined.

\section{Activity-Base Costing and the Theory of Constraints: The Effect of Changing Time Ho- rizons}

\section{A. The Applicability of Activity-Based Costing to Short-run Decisions}

Activity Based Costing has been primarily used as a technique to improve decisions involving long-run situations such as product selection and mix and facility sizing and location. However, for decisions with shorter time horizons, $\mathrm{ABC}$ has two major limitations: 1) a failure to distinguish between fixed and variable costs and 2) full absorption of cost that are partially sunk. Falconer $(1994,264)$ views this as a continuation of the long established management accounting issue of how to treat fixed and variable costs in income measurement.

Cooper and Kaplan (1992) have attempted to rebut the criticism leveled at $\mathrm{ABC}$ based on the technique's failure to discriminate between fixed and variable cost. The problem, they contend, is that "the conventional fixed versus variable cost classification arises from an attempt to classify the likely change in spending or supply of a resource...activity-based costing systems estimate the cost of resources used in organizational processes to produce output." While the supply of some activity resources is committed or fixed, ABC measures the extent to which these fixed resources are actually being utilized. By comparing activity costs from periodic financial statements (quantity supplied and available) with $\mathrm{ABC}$ cost data (quantity utilized), an organization can determine the amount of unused capacity or slack that exists in each activity. This helps to identify activities that are nearing capacity and therefore require the commitment of additional resources. It also identifies activities with substantial excess capacity that are candidates for capacity reduction in the long run.

For managerial decisions requiring in- 
cremental analysis, Cooper and Kaplan recognize that $\mathrm{ABC}$ analysis must be supplemented by additional "cash flow" studies to determine the incremental effects of various alternatives. However, they view ABC as an "integral calculus" which will narrow the large number of possible alternatives in a given decision situation to a few which can then be closely examined using incremental analysis. For short-run decisions, $A B C$ thus becomes an initial screen with produces a "short list" of alternatives to be further evaluated using incremental analysis. Implicit in this suggested approach is the assumption that all potentially feasible short-run alternatives will also be identified by $\mathrm{ABC}$ as feasible alternatives, i.e. be included on the "short list" for future investigation. Incremental analysis typically disregards costs which are "sunk" with respect to the decision at hand. Since ABC represents a type of full absorption costing, it would appear that some alternatives which would be rejected using $A B C$ (full $\mathrm{ABC}$ costs exceed revenues) might emerge is viable short-run alternatives once sunk costs are eliminated. The use of $\mathrm{ABC}$ as an initial screen as suggested by Cooper and Kaplan thus appears to reject potentially viable alternatives that should be considered in short-run analysis.

A recent article by Rao (1997) illustrates the problem associated with applying $A B C$ in situations involving sunk costs. Rao examined a decision by a major U. S. company to out source a seemingly less-profitable product so that it could concentrate production on a seemingly more profitable one. The result was a reduction in profitability rather than an increase. Rao contends the problem in this case was the use of direct labor as an allocation base in a situation involving a capital -intensive production process. "Traditional cost accounting had completely distorted the picture and given rise to lousy decisions." One factor involved in the "lousy decision" in this case was a failure to consider that the eliminated product was being produced with older full-depreciated equipment and the retained product on a newly-automated production line. Rao goes on to recommend $\mathrm{ABC}$ as a way of avoiding the "lousy decision" in this case. As a result, the labor-intensive product was being allocated a disproportionately large $\mathrm{ABC}$ might have utilized a more appropriate allocation base such as machine hours to allocate overhead or even treated equipment cost as a product-level cost associated with the decision to produce each product. However, the decision resulting from the use of $\mathrm{ABC}$ would probably still be "lousy" because the cost of existing capital equipment (whether or not fully depreciated) is a sunk cost that should be ignored. The only relevant considerations would be other alternative uses for the equipment and its disposal value. Improving the allocation of a cost that is irrelevant in a given situation does nothing to improve the quality of decisions resulting from its use.

\section{B. The Theory of Constraints - Its Usefulness Be- yond the Short Run}

As described above, the Theory of Constraints was developed primarily as a production management tool that focuses primarily on current production schedules. Because all costs are fixed (And therefore uncontrollable) the only way to improve profitability is by increasing throughput. Performance is thus measured in terms of effectiveness (attaining the maximum output from a given amount of inputs) as opposed to efficiency (maximizing the output obtained per unit of input). Measurement of efficiency has been the traditional focus of standard costing, which measures performance in terms of actual inputs (direct materials, direct labor and overhead) used in relation to a predetermined unit standard, based on the assumed controllability of these factors. By viewing inputs as fixed and uncontrollable, the Theory of Constraints eliminates the need for cost accounting information and focuses on throughput.

In all but the shortest - run situations, organizations have the ability to vary input levels in response to volume changes and other decisions that affect resource allocation. Both direct and indirect labor forces can be increased or downsized and, in the longer run, capital resources can be reallocated. Decisions of this nature require the ability to measure the effects produced by alternative changes in inputs. This 
implies the type of efficiency measurement traditionally provided by cost accounting. Goldratt $(1992,38)$ suggests that measuring the effects on cash flow is sufficient for this purpose. By using just-in-time inventory management, he assumes the virtual elimination of lags between cash flow and accrual accounting produced by inventory accounts. The results obtained are similar to those resulting from back-flush accounting. Increasingly, however, choices will involve questions of product selection and product mix that require the association of indirect costs with individual

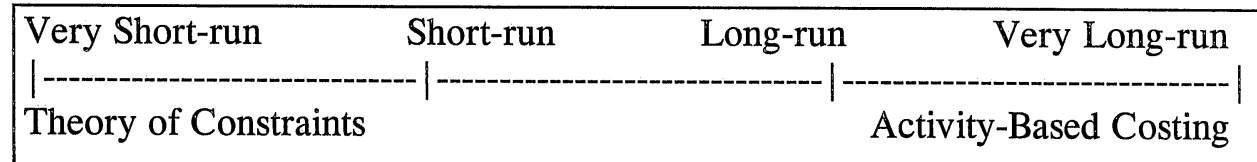

products. In this situation, the same problems of tracing costs (or cash flow effects as Goldratt chooses to characterize them) to product emerge as are present in activity-based accounting. As time horizons increase, the solutions produced by the theory of constraints begin to look more and more like those produced by conventional cost accounting techniques

\section{Activity-Based Costing and the Theory of Constraints - Different Costs for Different Uses}

Given the mostly fixed nature of shortrun decision costs and the mostly variable nature of these costs in the long run, it follows that the product costing techniques whose assumptions about cost most closely match each situation will produce better results than methods whose assumptions are different. Since the type of costs found in short-run decision situations are different from those in long-run decisions, it also follows that different costing techniques should be applied in each situation. Since it assumes that production costs are mostly fixed, Eliyahu Goldratt's Theory of Constraints appears to be best applicable to very short-run decision situations. Most of Goldratt's works are in fact primarily concerned with production scheduling and operations. His criticism of the use of full absorption cost information to make short-run decisions appears justified. The proportionality assumption implicit in activity-based costing requires that all costs be treated as variable ele- ments of product cost. This assumption makes this method most applicable to decisions involving long-run costs, particularly in such strategic planning areas as new product introduction, new ment of a long-run marketing strategy. The applicability of these two methods can be depicted as follows:

Decision Time Horizon: manufacturing process design, and the develop- 
be able to adjust to the results of these changes.

\section{Suggestions for Future Research}

The concentration of applications of activity-based costing in strategic planning is well documented. One of the implications of this paper is that applications of the Theory of Constraints be similarly concentrated on short-run problems. Surveys of actual applications could determine if these concentrations exist and also investigate the problems encountered by firms that use these methods in situations involving different time horizons (i. e., ABC in short-run decisions and TOC in long-run). The use of $\mathrm{ABC}$ as an initial screen for short-run decision solutions as suggested by Cooper in IV.A. above is another area for possible investigation. As described above, Cooper's method appears to have limitations. However, an improved screen, such as one based only on costs classified as batch level or below, might produce better results.

\section{Bibliography}

1. Cooper, Robin, "Five Steps to ABC Systems Design", Accountancy, November, 1990, pp. $78-81$.

2. _Cost Classification in UnitBased and Activity Based Manufacturing Cost Systems", Journal of Cost Management for the Manufacturing Industry, Fall, 1990, pp. 4-14.

3. , and Kaplan, R.S., "Activity-based

Casting Systems: Measuring the Costs of Resource Usage", Accounting Horizons, September, 1992, pp. 1-13.

4. Falconer, Michael, "A Commentary on the Applications of Activity-Based Costing", Management Accounting Research, Sep/ Dec 1994, pp. 261-277.

5. Ferrara, William L., "The New Cost/ Management Accounting: More Questions Than Answers", Management Accounting, October, 1991, pp. 48-52.

6. Goldratt, Eliyahu and Fox, R., The Goal.: North River Press, Croton-on-Hudson, NY, 1984.

7. "Late Night Discussions: XII:
How Cost Accounting Can Get In The Way", Industry Week, June 1, 1992, pp. 38-40.

8. Hornegren, C. T. and Foster, G., Cost Accounting: A Managerial Emphasis, 7th Ed., Prentice-Hall, Englewood Cliffs, NJ, 1991.

9. Johnson, H. T., and Kaplan, R., Relevance Lost: The Rise and Fall of Management Accounting, The Harvard Business School Press, Boston, MA, 1987.

10. , "It's Time to Stop Overselling Activity-Based Concepts", Management Accounting, September, 1992, pp. 26-35.

11. Koehler, Robert W., "Triple-Threat Strategy", Management Accounting, October, 1991, pp. 30-34.

12. McNair, C. J., Lynch, R. L., and Cross, K. F., "Do Financial And Non-Financial Performance Measures Have to Agree?", Management Accounting, November, 1990, pp. 28-36.

13. Rao, Srikumar S., "Cockeyed Overhead", Forbes, February 10, 1997, pp. 97-98.

14. Roth, H. P. and Borthick, A. F., "Are You Distorting Costs By Violating ABC Assumptions?", Management Accounting, November, 1991, pp. 39-42.

15. Woods, M. D., "Economic Choices With ABC", Management Accounting, December, 1992, pp. 53-57. 
